\title{
Laboratory Experiment and Numerical Analysis on the Precursory Hydraulic Process of Rainfall-Induced Slope Failure
}

\author{
Joon-Young Park (iD) and Young-Suk Song $(\mathbb{D}$ \\ Geo-Environmental Hazard Research Center, Geologic Environment Division, KIGAM, Daejeon 34132, Republic of Korea \\ Correspondence should be addressed to Young-Suk Song; yssong@kigam.re.kr
}

Received 27 September 2019; Revised 13 April 2020; Accepted 25 May 2020; Published 22 June 2020

Academic Editor: Kirk Hatfield

Copyright (C) 2020 Joon-Young Park and Young-Suk Song. This is an open access article distributed under the Creative Commons Attribution License, which permits unrestricted use, distribution, and reproduction in any medium, provided the original work is properly cited.

\begin{abstract}
A combined analysis involving a laboratory test and numerical modeling was performed to investigate the hydraulic processes leading to slope failure during rainfall. Through a laboratory landslide test in which artificial rainfall was applied to a homogeneous sandy slope, the timing and configurations of multiple slides were identified. In addition, volumetric water content was measured in real time through the use of monitoring sensors. The measured volumetric water content data were then used to validate the relevance of the numerical modeling results. The validated numerical modeling of the laboratoryscale slope failures provided insight into the hydraulic conditions that trigger landslides. According to the numerical modeling results, the miniaturized slope in the laboratory test was saturated in a manner so that the wetting front initially progresses downward and then the accumulated rainwater at the toe of the slope creates a water table that advances toward the crest. Furthermore, each of the five sequential failures that occurred during this experiment created slip surfaces where the pore-water pressure had achieved full saturation and an excessive pore-water pressure state. The findings of this study are expected to help understand the hydraulic prerequisites of landslide phenomena.
\end{abstract}

\section{Introduction}

The continually increasing issue of damage resulting from landslides is a result of global climate change. Analysis of the changes in Korea's 10-year average temperature and precipitation from 1912 to 2010 showed that the average temperature rose by 1.8 degrees Celsius and precipitation increased by $19 \%$ [1]. Statistics indicate that the average rainfall in summer is increasing, whereas the number of rainy days is decreasing. That is, the rainfall characteristics of summer are stronger than in the past, and rainfall intensity is also increasing. Due to the increase in localized heavy rainfall, landslides occur more frequently throughout the country, with the most notable case being the Umyeonsan landslide that occurred in July 2011. In the case of the Umyeonsan landslide, rainfall data of the adjacent Seocho, Namhyeon, and Gwanak observatories show that the hourly rainfall was $62.5 \mathrm{~mm}-94.0 \mathrm{~mm}$ at 8:00 am when the landslide occurred [2]. Landslide damage totaled 2,382 ha over the past 10 years $(53,295$ ha), with 53 casualties and 443 billion won in recovery costs.

Various research studies have focused on the occurrence of landslides and debris flows during rainfall, involving techniques such as theoretical analysis, numerical analysis, model experiments, and field monitoring. Recently, various types of laboratory model experiments have been conducted to analyze the mechanisms of landslides and slope failures. In Korea, certain studies were conducted to investigate the mechanism of landslides by causing failures under extreme artificial rainfall conditions [3, 4], whereas another study aimed to estimate the extent of spread after the occurrence of landslides [5]. In addition, Lee et al. [6] carried out experimental studies to investigate the characteristics of infiltration and drainage in model slopes during repeated rainfall. Kim et al. [7] conducted a series of landslide flume experiments to study responding sensitivities of various subsurface monitoring sensors. In the case of foreign countries, there are studies on landslide occurrence 
mechanisms according to slope shape [8] as well as studies on surface runoff and soil erosion according to rainfall characteristics [9]. The occurrence of slope failure under various slope conditions during rainfall was experimentally investigated by Acharya et al. [10]; Gallage et al. [11]; and Lourenco et al. [12].

Variables such as volumetric water content and porewater pressure are some of the most critical sources that govern transient causative factors of decreasing shear strength and the consequential loss of mechanical equilibrium. However, few studies have been conducted to comprehensively understand such precursory hydrologic and hydraulic behaviors that lead to the sliding of slopes. Although certain researchers [13-16] conducted purely experimental studies to investigate various changes in the subsurface during slope collapses, the findings could only provide insights at limited locations (i.e., locations of sensors).

With this context, this study conducted a laboratoryscale slope failure experiment in combination with numerical modeling to achieve comprehensive insights into the hydrologic and hydraulic processes of miniaturized and idealized landslides. For this purpose, a downsized sandy slope was formed and artificial rainfall was applied with a moderate intensity. During the experiment, the shape and type of the slope failures were analyzed, and the volumetric water content was monitored to be used as a prototype hydrologic variable in validating the relevance of the numerical modeling results. Thereafter, based on the numerical modeling results, the comprehensive saturation progress of the domain slope and the changes in the water flows that crossed boundaries (including runoff) were visually and quantitatively identified. Moreover, pore-water pressure conditions at the locations that formed slip surfaces were investigated by plotting numerically solved time-series data immediately prior to the failures.

\section{Experimental Configurations}

2.1. Apparatus of Laboratory Experiments. In order to simulate rainfall-induced slope failures and the corresponding subsurface hydrologic processes, experiments were performed using a set of laboratory test apparatus. Figure 1 shows a schematic diagram of the test apparatus, which is mainly comprised of a model chamber of a sandy slope, a rainfall simulation system, and a data management system: (1) The rainfall simulation system consists of a watering device with an oscillating nozzle, rainfall controller, and water tank. Rainfall intensity can be adjusted through the rainfall controller. (2) The data management system was installed to record the changes in hydrologic properties of the slope during rainfall. The instrument consists of TDR sensors, a data logger, and a computer. Decagon's 5TE soil moisture sensors were used as the TDR sensors to measure the change in the volumetric water content of the soil over time. Campbell Scientific CR1000M was used as the data logger to record data transmitted from the TDR sensors. (3) In the model chamber, a sandy slope was formed with a steep angle to be failure-prone under rainfall. As shown in
Figure 2(a), a sandy slope of a $35^{\circ}$ gradient was formed at the bottom of the chamber, which is inclined by $30^{\circ}$. The depth of the soil layer was set as $35 \mathrm{~cm}$ considering the scale of the model chamber. A total of four TDR sensors were installed in two rows at specified depths. The rainfall intensity was adjusted to $50 \mathrm{~mm} / \mathrm{h}$. Figure 2(b) shows a side view of the model chamber with the sandy slope. One side of the model chamber was made of transparent tempered glass to observe collapses of the slope. The model chamber was open at the toe of the slope. As a result, rainwater that either runs off the surface or infiltrates into the slope could be drained out to a bucket under the chamber.

2.2. Experimental Procedure. The purpose of this study was to observe slope failure and to investigate the hydrologic processes in homogeneous sandy slopes through a slope model test. The experiment was performed by setting a fixed rainfall intensity of $50 \mathrm{~mm} / \mathrm{h}$ and was carried out in the following order:

(1) A standard sample of Jumunjin sand from Korea was dried in an oven at $105^{\circ} \mathrm{C}$ for 24 hours and then additionally dried in air for 24 hours.

(2) Using compaction equipment with a rubber hammer and water sprayer, the dried sample was compacted in the model box and adjusted to $75 \%$ relative density with $4 \%$ volumetric water content. The compaction was conducted to ensure that the conditions of the model slope were homogeneous: (1) the soil mass and amount of distilled water required to produce the aforementioned density and wetness conditions were calculated using the given volume information of the model chamber; (2) three layers were compacted independently and piled up in sequence to ensure homogeneous and unified conditions.

(3) Four TDR sensors were installed at $10 \mathrm{~cm}$ and $25 \mathrm{~cm}$ from the bottom of soil.

(4) A rainfall intensity of $50 \mathrm{~mm} / \mathrm{h}$ was applied using the rainfall simulation system.

(5) The change in volumetric water content according to rainfall was measured and analyzed by the data management system in real time.

(6) The slope behavior was filmed in real time and failure shapes of the slope were analyzed over the elapsed period.

(7) The real-time monitored data on volumetric water content were analyzed and compared to the numerical modeling results of rainfall seepage.

(8) Hydraulic conditions on slip surfaces within the slope were simulated and analyzed using the numerical modeling results.

\section{Numerical Modeling Setup}

In this study, numerical modeling was conducted for rainfall infiltration and seepage water flow of the miniaturized landslide phenomena. The numerical modeling aimed to 


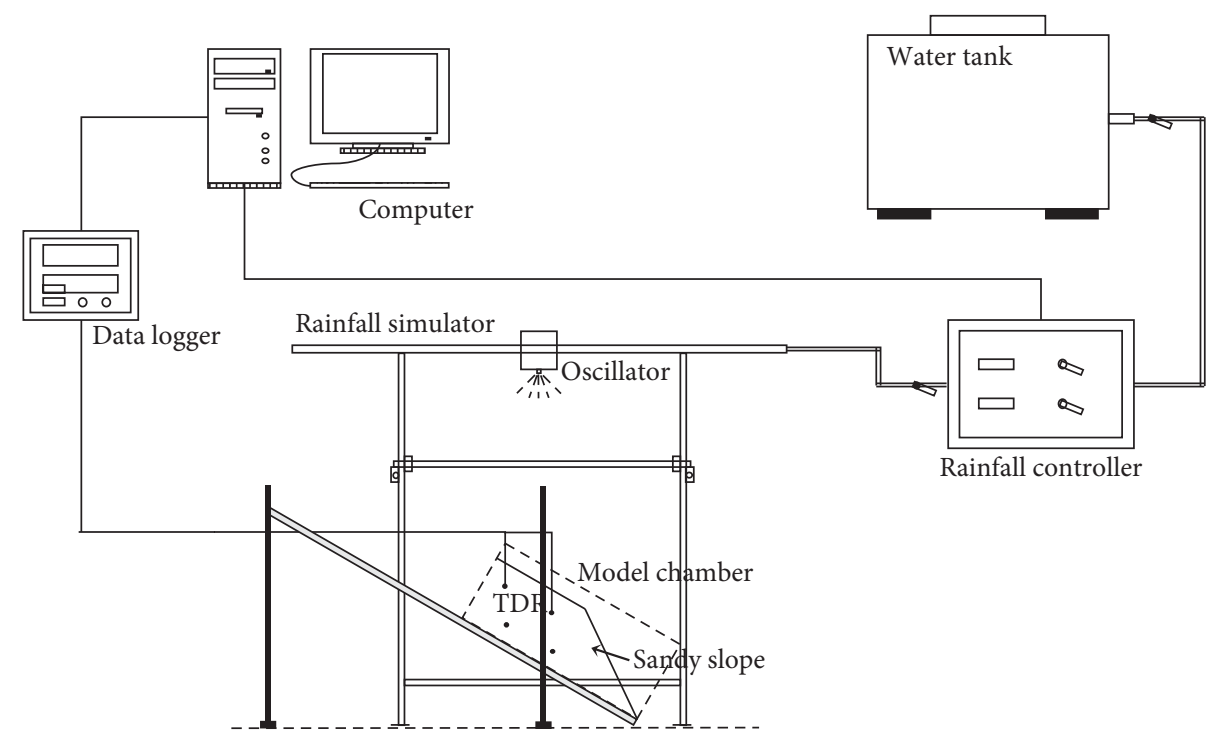

Figure 1: Schematic diagram of the model test apparatus.

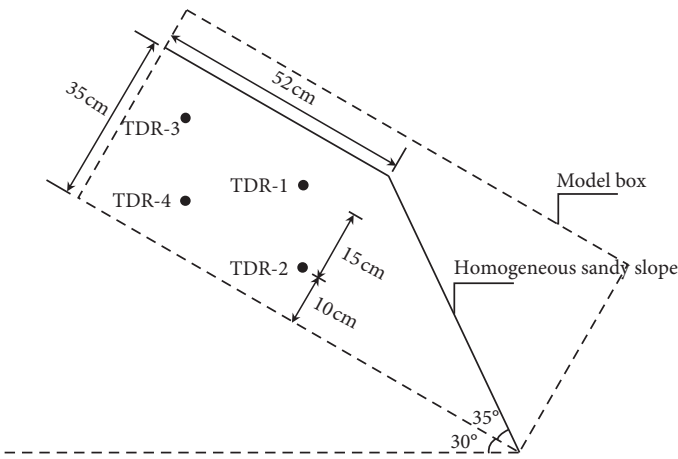

(a)

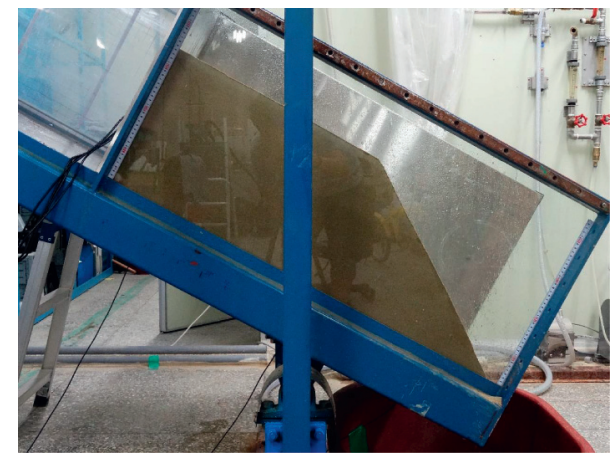

(b)

Figure 2: Model chamber of the sandy slope. (a) Geometry of the model slope and configuration of sensors. (b) Side view.

derive effective and valid data of hydraulic variables at any given point in the experiment domain, thereby assisting in understanding comprehensive hydraulic processes that lead to landslides. Field and laboratory experiments can only provide limited information with respect to these purposes. In the following sections, the components of the numerical modeling, such as material properties, domain geometry, and boundary and initial conditions, are specified in detail.

3.1. Material Properties. In order to construct the model slope composed of dense sandy ground for the laboratory experiment, Jumunjin standard sand was compacted to a relative density of $75 \%$. Based on an ASTM test method (ASTM D 4254-83), the maximum and minimum dry unit weights were calculated. A series of laboratory tests were conducted to analyze the physical properties of Jumunjin standard sand. As shown in Table 1, the specific gravity is 2.62, the effective particle diameter is $0.42 \mathrm{~mm}$, and the uniformity and curvature coefficients are 1.5 and 1.0, respectively. As a result, the sample falls within SP according to the Unified Soil Classification System. Figure 3 shows the grain size distribution curve of Jumunjin standard sand. Considering that the slope of the curve is steep in the range between 0.4 and $0.9 \mathrm{~mm}$, it is deduced that the particle size distribution is uniform.

In terms of unsaturated soil properties, Song et al. [18] used automatic test equipment to determine curve-fitting parameters for soil-water characteristic curves (SWCC) of Jumunjin standard sand with a relative density of $75 \%$. The tests were conducted for both drying and wetting paths of SWCC. Based on the measurement dataset of matric suction and volumetric water content, SWCCs were fitted by applying the van Genuchten [19] model. Accordingly, the model parameters were determined for both the drying and wetting paths, as summarized in Table 2. Figure 4(a) depicts the drying and wetting paths of the fitted SWCC [17]. On the other hand, unsaturated hydraulic conductivity functions were estimated for both the drying and wetting paths based on the van Genuchten-Mualem approach $[19,20]$ and the aforementioned SWCC fitting parameters (Figure 4(b)). Drastic shifts in the slope of the SWCC above and below a 
TABLE 1: Geotechnical engineering properties of Jumunjin standard sand.

\begin{tabular}{lcc}
\hline Description & Symbol & Measured value \\
\hline Specific gravity & $G_{s}$ & 2.621 \\
Max. dry density & $\gamma_{d \cdot \max }$ & $1.613 \mathrm{~g} / \mathrm{cm}^{3}$ \\
Min. dry density & $\gamma_{d \cdot \min }$ & $1.366 \mathrm{~g} / \mathrm{cm}^{3}$ \\
Effective particle size & $D_{10}$ & $0.42 \mathrm{~mm}$ \\
Uniformity coefficient & $C_{u}$ & 1.5 \\
Coefficient of curvature & $C_{c}$ & 1.0 \\
Soil classification & $\mathrm{USCS}$ & $\mathrm{SP}$ \\
Internal frictional angle & $\Phi^{\prime}$ & $41.2^{\circ}$ \\
\hline
\end{tabular}

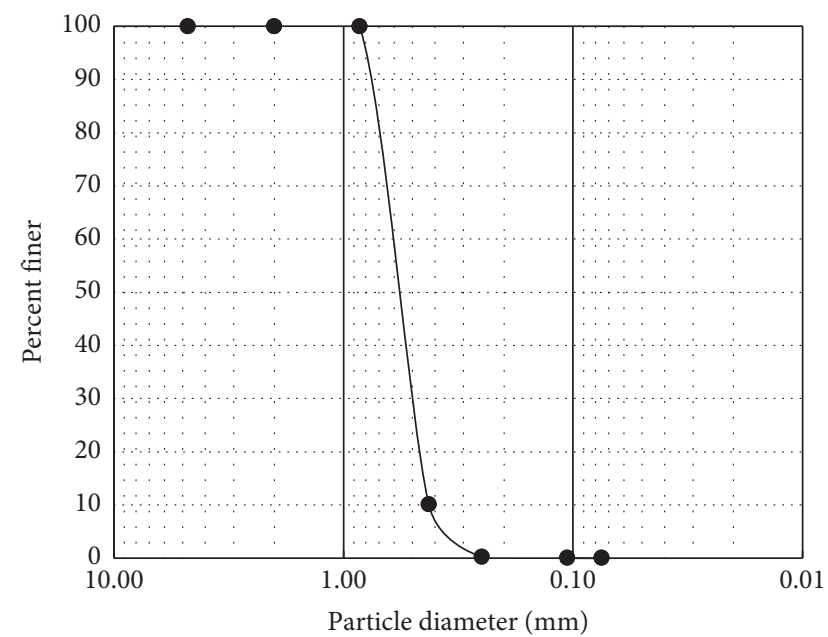

Figure 3: Grain size distribution curve of Jumunjin standard sand [17].

particular range of matric suction values (approximately $1 \sim 4 \mathrm{kPa}$ ) imply that unsaturated soil samples are expected to undergo drastic shifts in the matric suction decrement rate according to regular increments of degree of saturation. More specifically, samples with dry conditions will rapidly lose its high matric suction as it is wetted, until it reaches $\sim 4 \mathrm{kPa}$ matric suction (the first shifting section). Thereafter, matric suction will decrease at a drastically slower rate at the regular influx rate, whereas unsaturated hydraulic conductivity and consequential infiltration rate sharply increase. As the sample reaches near-full saturation at $\sim 1 \mathrm{kPa}$ matric suction (also referred to as the air-entry value), the second shifting section begins, where the remaining low matric suction will be rapidly lost by a small amount of influx until the fully saturated sample starts to exhibit excessive porewater pressures. Due to the hysteresis behavior in unsaturated soils, the wetting path results in a lower effective saturation than the drying path, which in turn leads to a lower saturated hydraulic conductivity for the wetting path compared to the drying path (Table 2).

3.2. Numerical Domain and Boundary Conditions. The commercial finite element numerical code, SEEP/W (GeoSlope International Ltd., 2012), was used to describe the rainfall infiltration and subsurface water flow of the experiment in this study. Figure 5 depicts the geometry of the domain (model slope) where a discretized mixed quad and triangle mesh is created. The element size was set to $1.5 \mathrm{~cm}$, which led to the formation of the entire mesh comprised of 1409 nodes and 1325 elements. As the slope material (Jumunjin standard sand) was compacted and formed to an extent that it possesses a spatially uniform volumetric water content of $4 \%$, the corresponding ground pore-water pressure was estimated as $-3.5 \mathrm{kPa}$ based on the SWCC (Figure 4(a)). This negative pore-water pressure value that is constant regardless of depth was set as an initial condition of the domain through steady-state analysis. As for the transient analysis that was conducted in sequence, several different types of boundary conditions were applied: (1) a constant zero flux condition was assigned to the left side edge and the bottom of the domain; (2) a constant rainfall flux of $50 \mathrm{~mm} / \mathrm{h}$ (or $1.39 \mathrm{E}-03 \mathrm{~cm} / \mathrm{s}$ ) was applied to the two upper edges that represent the ground surface. This rainfall flux rate was set as almost equal to the saturated hydraulic conductivity of Jumunjin standard sand (see Table 2) to prevent predominant overflowing as well as erosive losses of surficial soil. Through a series of laboratory experiments, Kim et al. [21] found that if the rainfall intensity is less than four times the saturated permeability of the ground, rainfall infiltrates the ground without much surface runoff while maintaining the saturation form as wetting-band progressions. It should be noted that, in the experiment, rainfall from the oscillating nozzle did not reach both ends of the soil, only reaching up to approximately $10 \mathrm{~cm}$ from each end of the slope surface. Therefore, the entire two upper edges (i.e., the slope surface) were set as a potential seepage face so that the boundary conditions of the nodes on the slope surface are reviewed at the end of each iteration to check if the conditions meet correct criteria and make adjustments as necessary. The settings would determine the desirable scale of the required seepage face for each time step. At the same time, the analysis was set to prevent rainwater from ponding on the slope surface boundary conditions. Instead, surface water was assumed to be immediately lost via runoff; this setting was possible in Seep/W with the precondition that a surface layer mesh with fine discretization exists on the slope surface boundaries (refer to the zoomed-in part of Figure 5). If numerical analysis is conducted for rainfall infiltration without constructing the surface layer mesh, excessive water that failed to infiltrate the ground would stack up and apply additional load, increasing positive pressure heads to any points located underground of the slope.

\section{Results and Discussion}

4.1. Retrogressive Failure and Analysis of Hydrologic Processes. Figure 6 shows five failures that sequentially occurred in the sandy slope during the experiment of this study. As $95 \mathrm{~min}$ elapsed after the beginning of the rainfall, a marginal failure was first observed at the toe of the slope as an initiator of four successive slope failures that occurred within $25 \mathrm{~min}$ (from Figures 6(a)-6(d)). The failure scale gradually expanded, and thereafter, with a long interim dormant period of $111 \mathrm{~min}$, the largest and final slope collapse was recorded at the 
TABLE 2: Unsaturated soil parameters of Jumunjin standard sand with a relative density of $75 \%$.

\begin{tabular}{cccccccc}
\hline \multirow{2}{*}{ Condition } & \multicolumn{3}{c}{ van Genuchten [19] SWCC fitting parameters } & \multicolumn{3}{c}{ Saturated hydraulic conductivity } \\
& & $\alpha\left(\mathrm{kPa}^{-1}\right)$ & $n$ & $m$ & $\theta_{s}$ & $\theta_{r}$ & $k_{s}(\mathrm{~cm} / \mathrm{s})$ \\
\hline \multirow{2}{*}{$D_{r}=75 \%$} & Drying & 0.393 & 8.553 & 0.883 & 0.41 & 0.03 & $1.887 \times 10^{-3}$ \\
& Wetting & 0.593 & 5.561 & 0.820 & 0.39 & 0.03 & $1.482 \times 10^{-3}$ \\
\hline
\end{tabular}

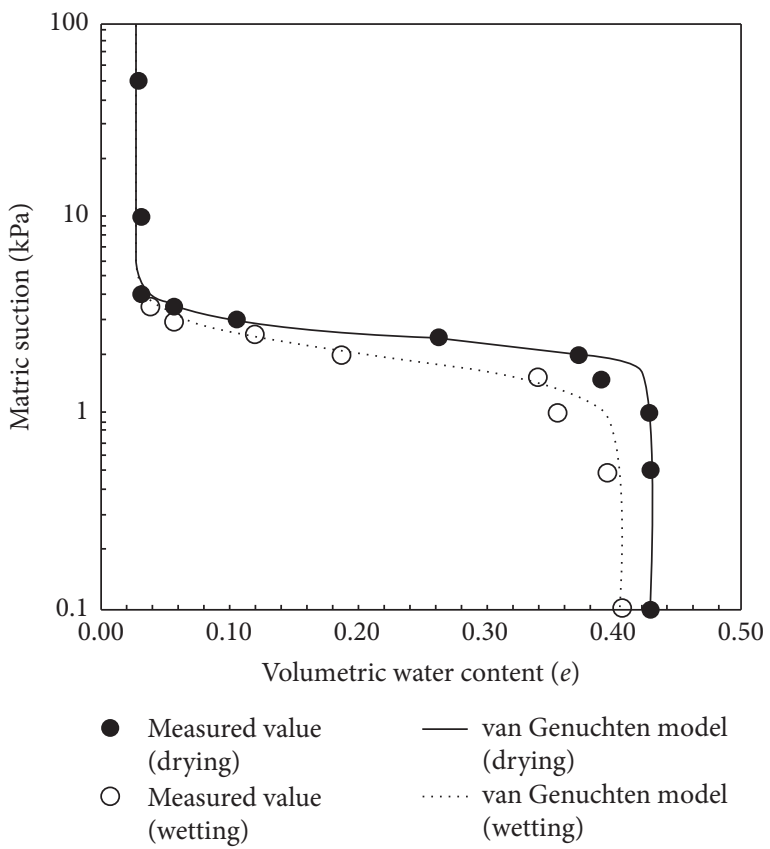

(a)

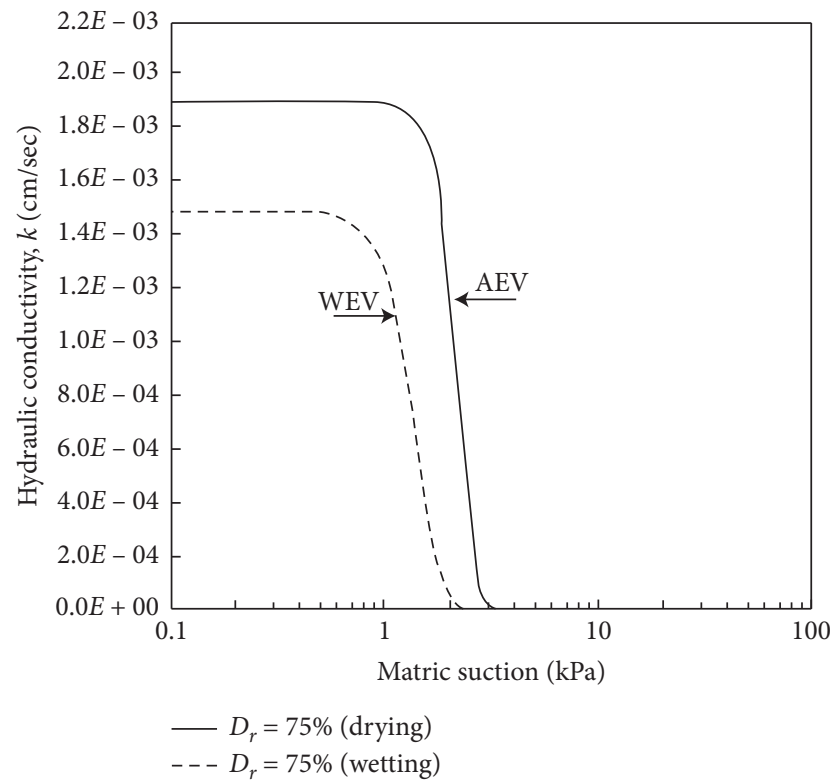

(b)

FIGURE 4: Unsaturated properties of Jumunjin standard sand with a relative density of 75\% [17]. (a) SWCC. (b) Unsaturated hydraulic conductivity function.

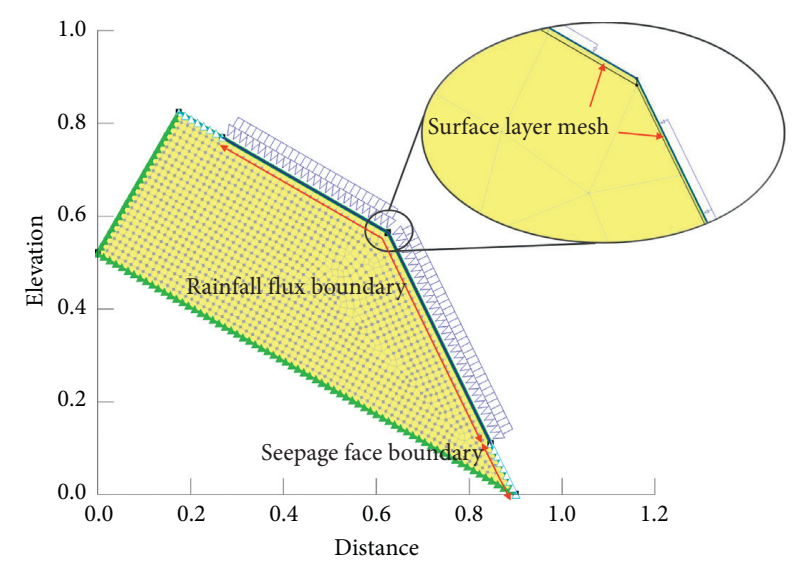

FIGURE 5: Domain and boundary conditions of seepage modeling and zoomed-in view of the surface layer mesh.

elapsed time of $239 \mathrm{~min}$ (Figure 6(e)). The characteristic failure mode that was observed in this study is deemed relevant as most precedent studies that conducted similar laboratory experiments on landslide initiation by applying moderate-intensity rainfalls on sandy slopes observed a common slope failure phenomenon, the so-called retrogressive failure (e.g., Reid et al. [15]; Lourenço et al. [16]; and Wu et al. [22]). That is to say, multiple sequentially occurring slides progressed toward the crest (upslope), and these were accompanied by initial local failures or surface erosions at the toe of the slope.

Figure 7 shows the rainfall seepage process of the model slope that were computed from the numerical modeling. Initially, rainfall infiltrated the ground, advancing the wetting front downward (Figure $7(\mathrm{a})$ ). The subsurface water flow tended to converge downslope and built up a water table from the toe of the slope where the drainage face is located (Figure 7(b)). Subsequently, the created water table progressively extended upslope (Figure 7(c)). However, after rising to a certain elevation, the water table maintained a constant elevation regardless of rainfall infiltration, as shown in Figure $7(d)$.

In order to verify the numerical modeling results, volumetric water content data as monitored by the four TDR sensors in the experiment were compared with the numerically solved volumetric water content data at the same locations (Figure 8). (1) Volumetric water content responded (by abruptly rising) when the wetting front or water 


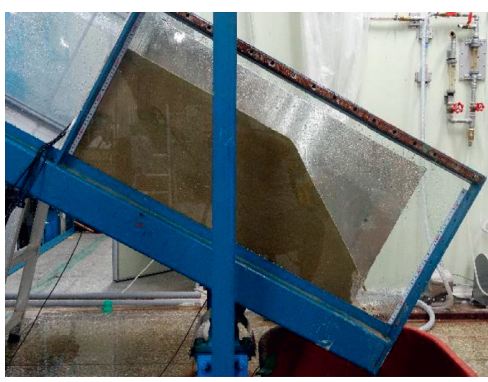

(a)

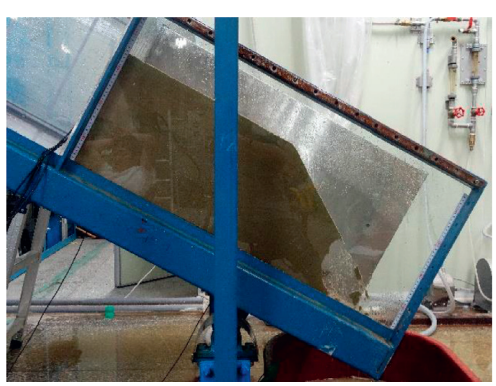

(d)

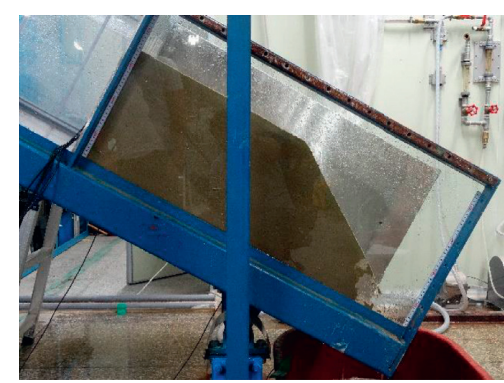

(b)

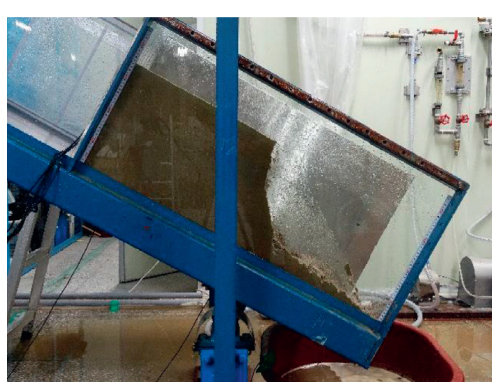

(e)

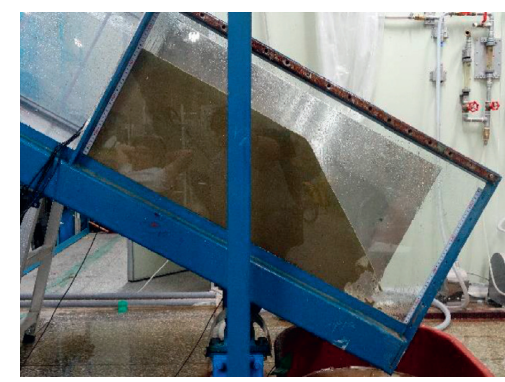

(c)

FiguRE 6: Side view of the slope at each moment of failure: (a) 1st failure (after $95 \mathrm{~min}$ ); (b) 2nd failure (after 103 min); (c) 3rd failure (after $114 \mathrm{~min}$ ); (d) 4th failure (after $128 \mathrm{~min}$ ); (e) 5th failure and test completed (after $239 \mathrm{~min}$ ).

table reached the measurement location. Therefore, the locations of TDR 1 and TDR 2, which are located relatively downslope, responded earlier than the other two locations. Moreover, TDR 1 was the first to respond as it was located closer to the ground surface than TDR 2. With the exception of the location of TDR 4, the response times of the other three locations in the experiment sufficiently coincided with the response times from the modeling results. As for the failure to predict the response of TDR 4, under the assumption that the sensors did not malfunction during the experiment, the water table may not have actually reached the bottom depth of the upslope where TDR 4 was located (refer to Figure 2(a) for the configuration of the TDR sensors). This may be due to the fact that the bottom layer of the soil was compacted to a relatively lower density, meaning that its drainage capacity was actually larger. (2) The measured volumetric water contents from the four sensors did not reach saturated conditions due to an experimental limitation: the soil was not compacted uniformly enough near the sensor locations to prevent the instruments from being damaged. This possibly led to larger voids in the soil and lower saturated water content values. (3) The volumetric water content of Modeling_TDR 3 exhibited a relatively gradual increase in the saturation progress and was overtaken by that of Modeling_TDR 4 from approximately the time of the 4th failure (refer to Figure 8). This is due to the water table progression shape: namely, in the upslope part near the crest, the downward-moving wetting front reached the shallow depth soil (i.e., the TDR 3 location) before the groundwater level reached the bottom depth soil, resulting in the shallow depth soil experiencing a matric suction loss earlier than the bottom depth soil (refer to Figure $7(a)-7(c)$ ). However, after the 4 th failure, the bottom depth soil (i.e., the
TDR 4 location) was occupied by the water table and entered into a positive pore pressure state earlier than the shallow depth soil (refer to Figure $7(\mathrm{~d})$ ). (4) Despite the aforementioned discordances at the TDR 4 location, it was concluded that the numerical modeling results are effective enough to represent hydraulic behaviors preceding slope failures. This is due to TDR 4 being located relatively far upslope of the failure locations among all sensors. In other words, the hydrologic conditions of the TDR 4 location were less likely to have significantly influenced the hydraulic behaviors at the failure interfaces.

The authors did not directly measure the amount of runoff during the experiment as runoff was not a significant factor governing the slope failure phenomena in this study. As aforementioned in Section 3.2, the artificial rainfall in the experiment was set to a sufficiently mild level to enable full penetration into the ground without producing runoff in the beginning stages. This facilitated the focus on subsurface hydrologic processes leading to failure. Additional experiments with smaller rainfall intensities were not conducted as the overall saturation progress prior to slope failure was expected to be similar with the only difference being in pace. The numerical analysis results that effectively represent the experiment also verify these assertions. Figure 9 shows the numerical analysis results of the changes in comprehensive rainwater flow rate across the boundaries (i.e., slope surface) over time. In Figure 9(a), positive values refer to flows into the system, whereas negative values refer to flows out of the system. Accordingly, it is interpreted that rainfall totally infiltrated the slope and no water was lost in the beginning through either runoff or the seepage face. However, from 52 to $53 \mathrm{~min}$ after rainfall initiation, a water table was created, which began to rise. The seepage face boundary nodes 


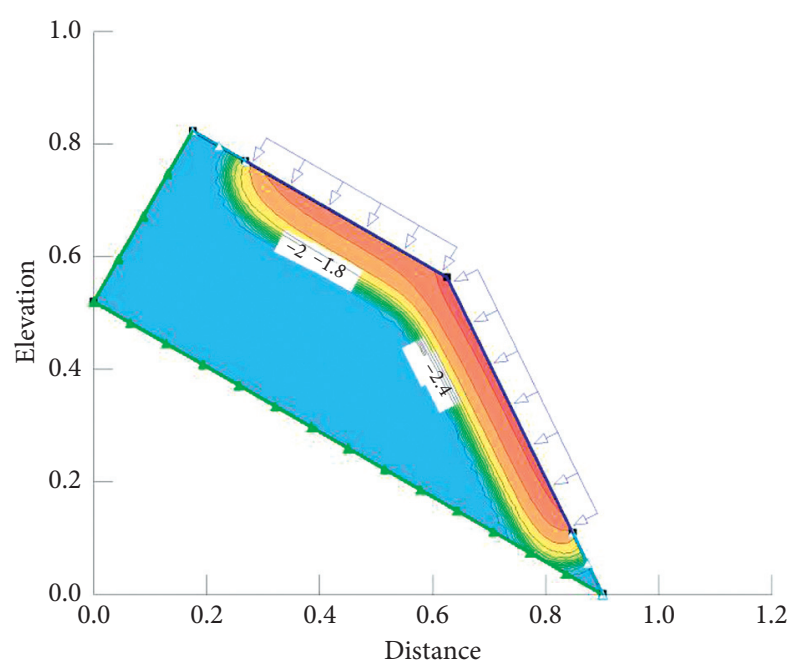

(a)

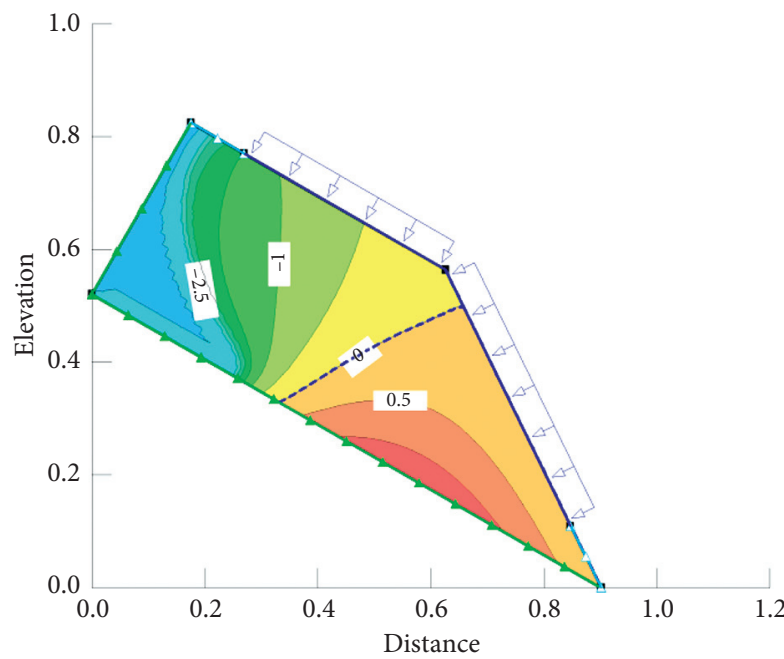

(c)

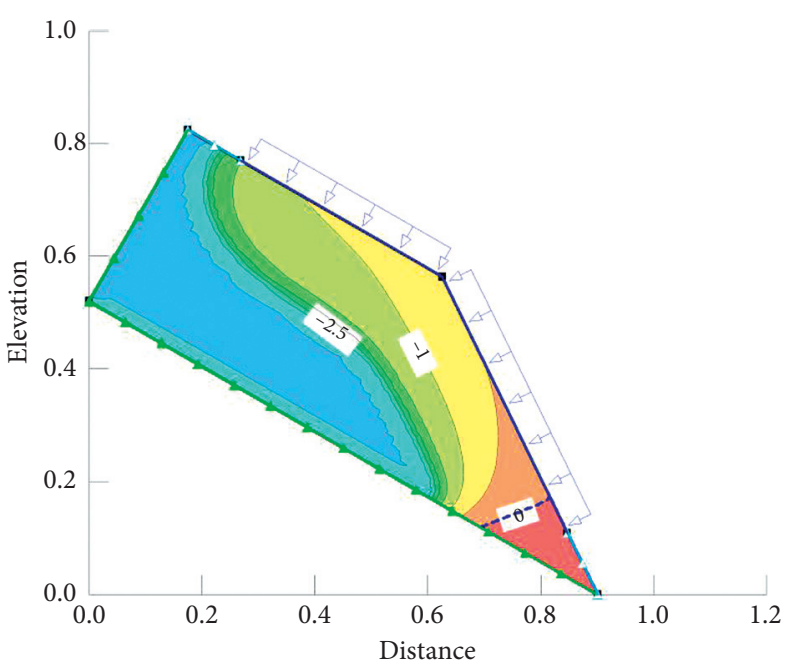

(b)

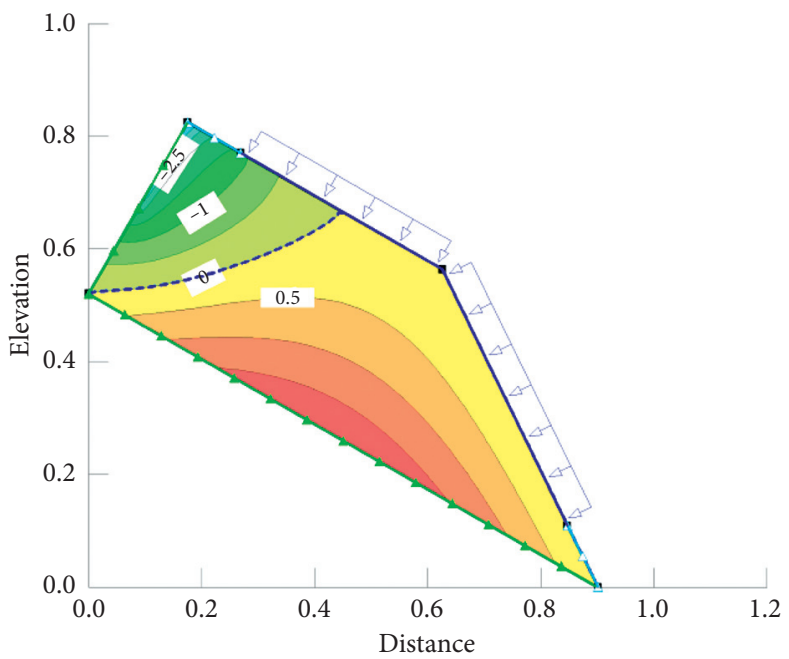

(d)

FigURE 7: Seepage flow modeling results corresponding to elapsed times of (a) $30 \mathrm{~min}$; (b) $60 \mathrm{~min}$; (c) $128 \mathrm{~min}$ (at 4th failure); (d) 239 min (at 5th failure).

immediately discharged water as the nodes were overcome by the water table. Sequentially, the rainfall flux boundary nodes started to lose portions of the rainfall influx as runoff as the rising water table reached the nodes (refer to Figure 5 for the two boundary sections and refer to Figures 7 and 10 for the water table locations at various critical times). In the case of certain rainfall flux boundary nodes located at lower elevations, total rainfall influxes were lost as runoff and subsurface water flows were discharged as the water table continued to increase in elevation. Rainfall flux boundary nodes at higher elevations with gentler slopes lost significantly lower amounts of rainfall influx despite being surpassed by the water table. In Figure 9(b), the variation of the total runoff flow across the slope surface was plotted with respect to time. This was possible by subtracting the total amount of water flow that crossed the boundaries from the amount of total rainfall rate across the slope surface at each time step. The total amount of runoff flow gradually increased and approached the total rainfall rate. This indicates that, as time elapsed to the end, only a small amount of rainfall could infiltrate at a few boundary nodes near the crest of the slope, whereas most of the rainfall overflowed the slope as runoff. Conclusively, it can be speculated that if the same experiment is conducted with smaller rainfall intensities, it will take longer for a water table to be formed and the elevation of the water table will increase at a slower rate. However, the overall pattern of water flux evolutions across the boundaries will be maintained.

4.2. Pore-Water Pressure Conditions Leading to Failure. The relevance of the numerical modeling results in representing hydrologic processes of the laboratory experiment was validated through a comparative study of volumetric water content responses in Section 4.1. As a result, using the numerically solved data, observations of equivalent hydraulic processes prior to failure are possible at specific locations including slip surfaces. Figure 10(a) describes the 


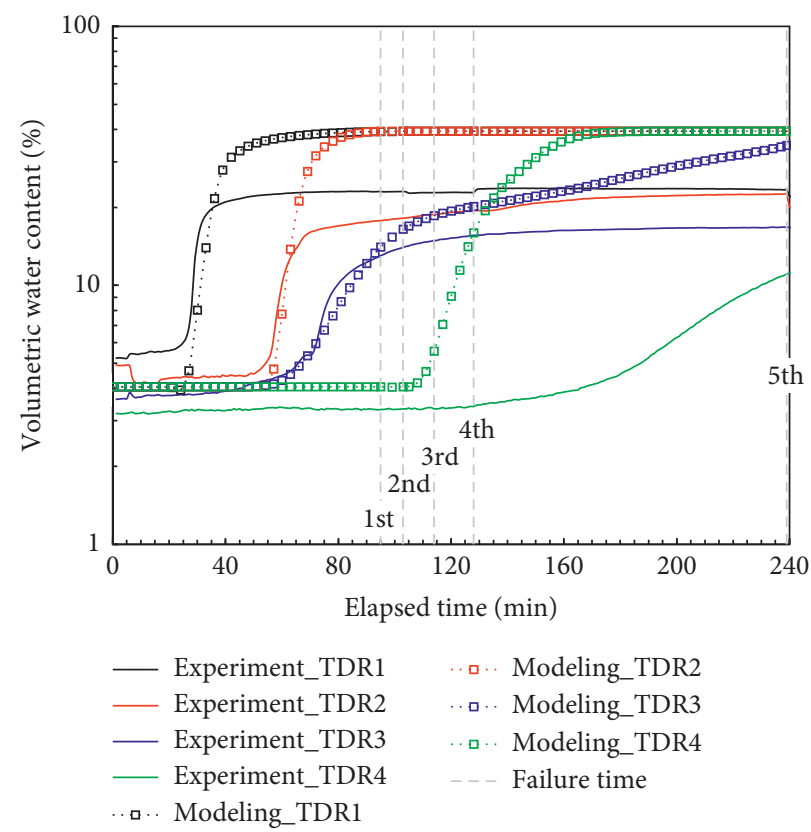

FIGURE 8: Comparison between the experiment and modeling results in terms of volumetric water content changes with respect to elapsed time at the four TDR sensor locations.

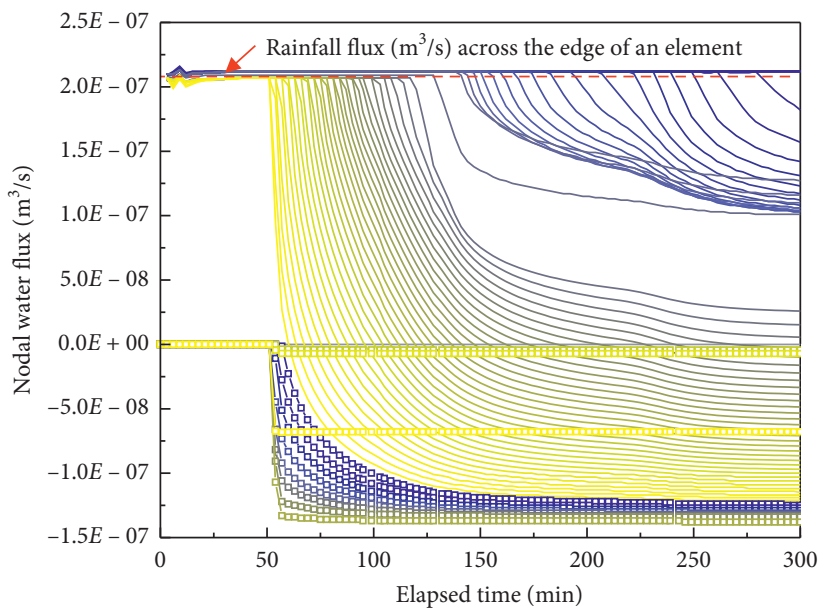

(a)

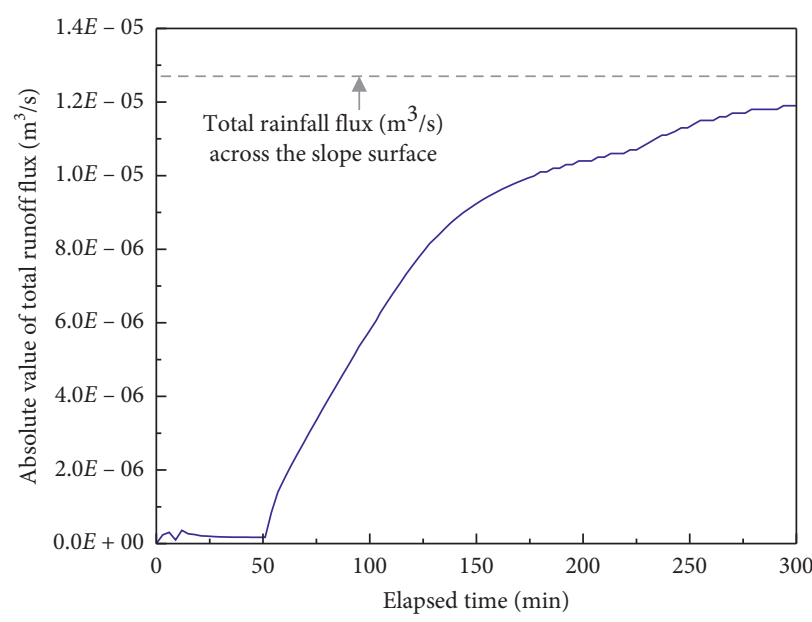

(b)

FIGURE 9: Change in comprehensive water flow across boundaries (i.e., slope surface) over time. (a) Individual nodal flow. (b) Total runoff flow. *The group of line plots are from the rainfall flux boundary nodes, whereas the group of "line and symbol" plots are from the seepage face boundary nodes (refer to Figure 5 for the two boundary section). ${ }^{* *}$ On a color spectrum from blue to yellow, the darkest blue line indicates a node at the highest elevation, whereas the brightest yellow line indicates a node at the lowest elevation. The color spectrum is applied to the two groups of plots independently.

slip surface shapes and configurations of the five failures that occurred in the experiment. The slip surface of the final 5th slope failure was larger than the slip surfaces of the first four failures. In the numerical modeling domain, the element node locations that correspond to the slip surface locations were selected and flagged as blue dots (from Figures 10(b)10(f)). Finer discretization will be needed to select nodes of more exact locations that create smoother slip surfaces in future studies. In this study, pore-water pressure time-series data on the five slip surfaces, namely, the blue dots in
Figure 10, were collected and analyzed to determine the behavioral characteristics of pore-water pressure prior to the moment of failure. Figure 11 shows the plot of pore-water pressure evolutions leading to the five consecutive failures at the nodes corresponding to slip surface locations. Among these nodes, the nodes at shallow depths or the ground surface underwent abrupt losses of matric suction earlier than the nodes close to the bottom in the initial stages of the experiment. This was because the nodes at shallower depths were accessed more quickly by the downward-moving 


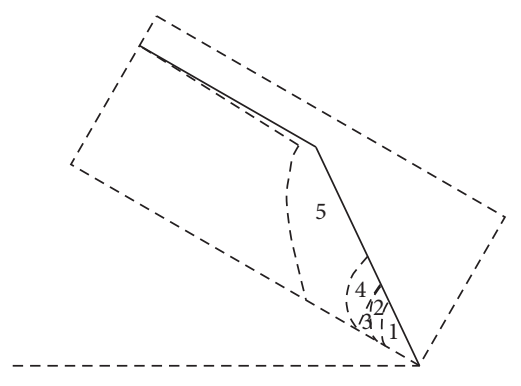

(a)

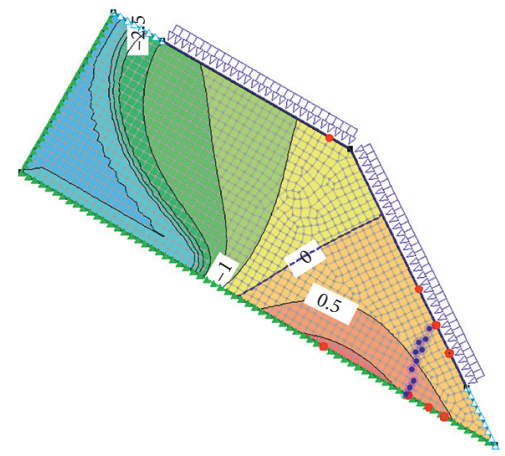

(d)

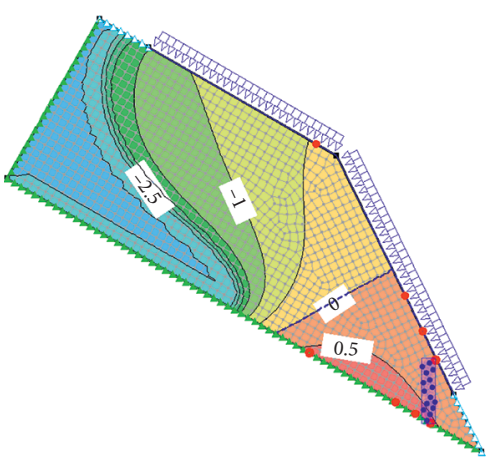

(b)

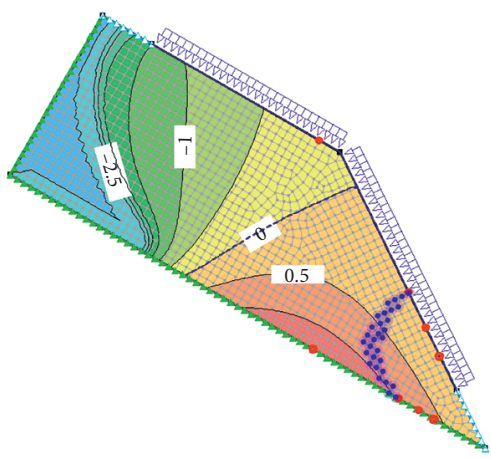

(e)

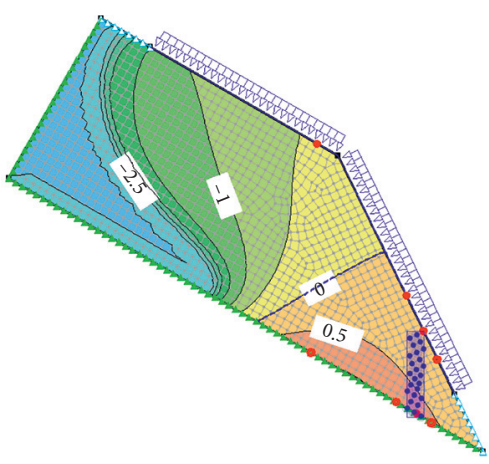

(c)

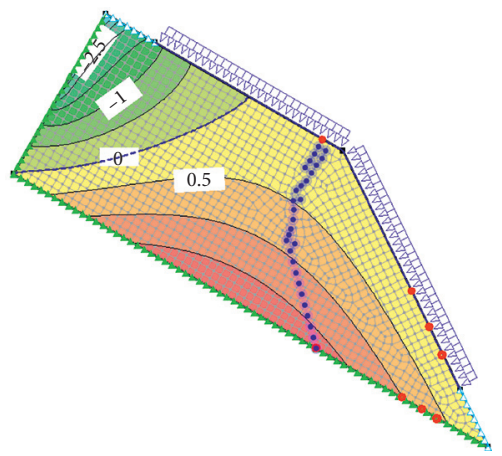

(f)

FIGURE 10: Slip surface shapes (a) and measuring points (blue dots) of pore-water pressure that constitute the slip surface of the (b) 1st failure; (c) 2nd failure; (d) 3rd failure; (e) 4th failure; (f) 5th failure.

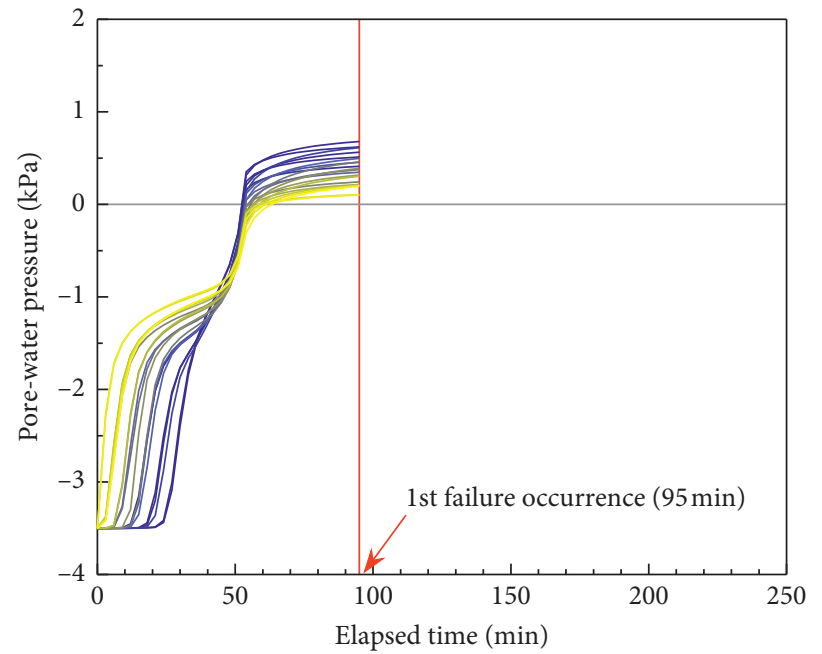

(a)

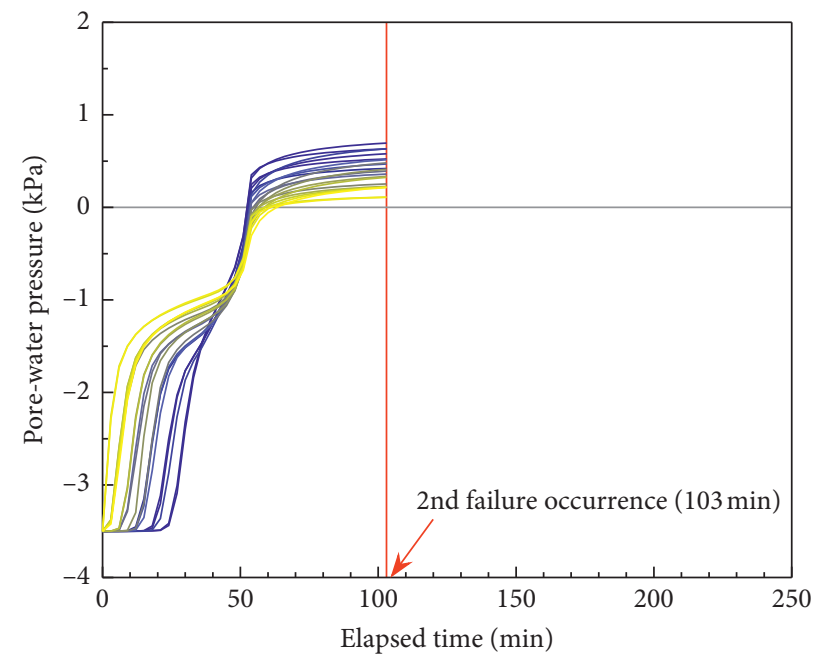

(b)

Figure 11: Continued. 


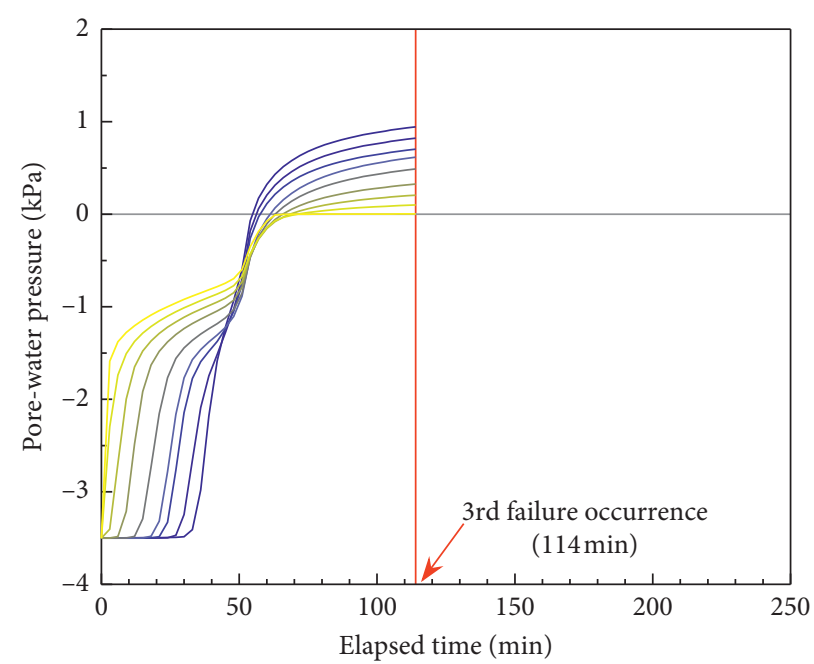

(c)

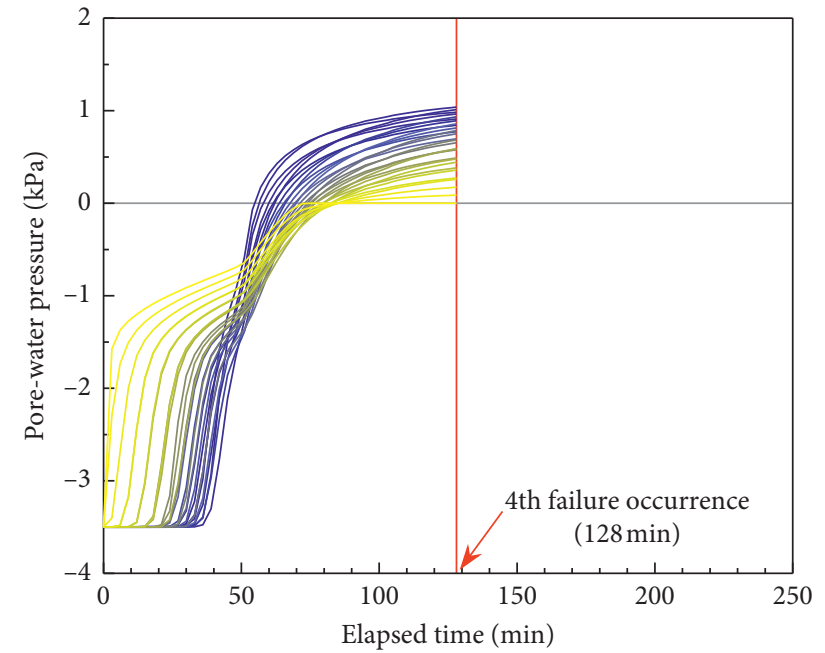

(d)

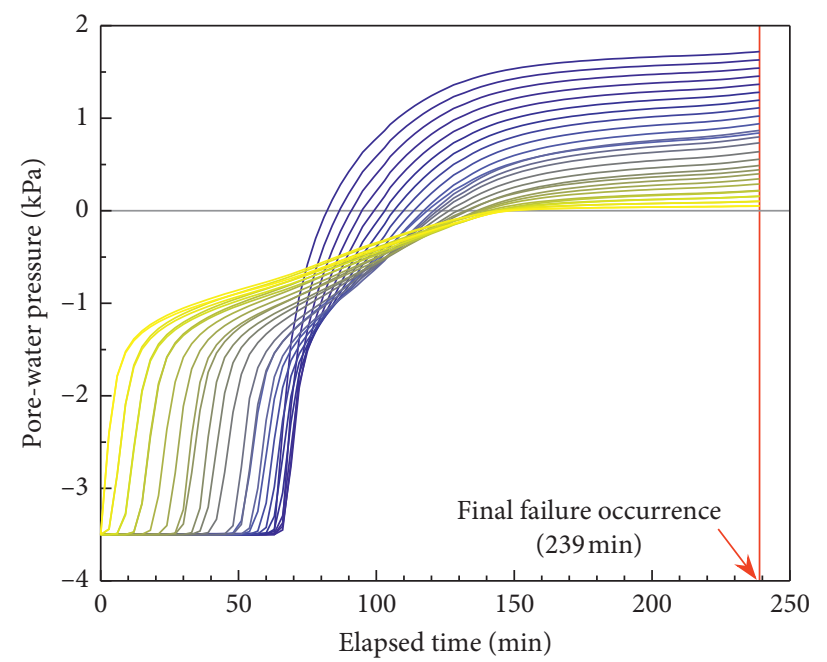

(e)

FIGURE 11: Evolutions of pore-water pressure leading to the five consecutive failures at the nodes corresponding to slip surface locations. * On a color spectrum from blue to yellow, the darkest blue line indicates a node at the lowest elevation, whereas the brightest yellow line indicates a node at the highest elevation. (a) At nodes corresponding to the 1st slip surface. (b) At nodes corresponding to the 2nd slip surface. (c) At nodes corresponding to the 3rd slip surface. (d) At nodes corresponding to the 4th slip surface. (e) At nodes corresponding to the 5 th slip surface.

wetting front. On the other hand, the nodes at lower elevations generally exhibited greater excessive pore-water pressures as the elapsed time approached the moments of failure. This was because failures occurred below the water table (refer to Figure 10); thereby, the positive pore-water pressures of the nodes corresponding to slip surface locations were proportional to the corresponding vertical distance to the water table. From this analysis of the pore-water pressure conditions leading to the five failures, it was deduced that, in the case of sandy slopes, slope failure may occur when several prerequisites are satisfied: the soil at the expected slip surface is fully saturated and exhibits excessive pore-water pressure due to a water table that has been elevated to the ground surface or above the expected slip surface.
It should be noted that scale effects did not significantly lower the reliability of the results in this study despite being a well-known essential problem of small-scale experiments. This is because scale effects in landslide phenomena mainly involve stress conditions during sliding and consequent flow movement characteristics, not hydrologic or hydraulic processes prior to sliding. For example, dimensional analysis [23] is a powerful method that has been favored by researchers to "scale down" debris flow mixtures for laboratory experiments while maintaining geometric, dynamic, and kinematic similarity (e.g., [24-26]). Iverson et al. [13] also found that changes in pore-water pressure exerted by changes in volume of the soil mass (consolidation or swelling) during sliding depend on the initial porosity and the relative time scales for soil deformation and pore- 
pressure diffusion. Therefore, this initial porosity condition has been a pivotal factor in laboratory experiments for simulating debris flow mobilizations. Despite such possible dissimilarities from full-scale natural phenomena in terms of the stress conditions during sliding and postfailure behaviors, the laboratory experiment in this study is deemed validated as the scope of this study focuses on providing insight into comprehensive hydraulic processes "prior to" slope failures.

\section{Conclusions}

In this study, hydrologic and hydraulic processes of the overall domain area that entailed multisliding landslides were identified through a combined analysis involving a laboratory experiment and numerical modeling. Furthermore, hydraulic prerequisites (or pore-water pressure conditions) for triggering landslides in sandy slopes were understood. Model experiments were carried out on homogeneous soils, and the saturation pattern of the slope due to rainfall infiltration was investigated using measuring devices and numerical modeling techniques. Furthermore, we described the slip surface shapes and configurations to identify the slip surface locations. Based on these locations, the evolutions of numerically solved pore-water pressure data leading to the failures were traced. Additional findings of this study are summarized as follows:

(1) The model slope was observed to be saturated during rainfall from the surface to the bottom and thereafter from the toe to the crest due to the wetting front's downward progress and the subsequent water table increase, respectively.

(2) The failure mode of the model slope was a retrogressive failure that started from the toe of the slope and subsequently extended upslope to the top of the slope. The slip surface was formed as a rotational failure type.

(3) The response times of volumetric water content derived from the numerical modeling sufficiently coincided with the results from the experiment. The numerical modeling results were reasonable to represent the hydraulic processes of the model slope in the experiment.

(4) The slope failures occurred as several subsurface hydraulic conditions were satisfied: full saturation, excessive pore-water pressure, and the hydrostatic pressure state.

\section{Data Availability}

The laboratory test and numerical modeling data used to support the findings of this study are available from the corresponding author upon request.

\section{Conflicts of Interest}

The authors declare that they have no conflicts of interest regarding this work.

\section{Acknowledgments}

This research was supported by the Basic Research Project (no. 20-3412-1) of the Korea Institute of Geoscience and Mineral Resources (KIGAM) funded by the Ministry of Science and ICT of Korea.

\section{References}

[1] Korea Institute of Geoscience and Mineral Resources (KIGAM), A Study on the Early Warning Technology of Landslides in Natural Terrain Under Extreme Rainfall through the Stereotactic Monitoring (2012M3A2A1050983), National Research Foundation of Korea, Ministry of Science, ICT and Future Planning, Daejeon, Republic of Korea, in Korean, 2017.

[2] Korean Geotechnical Society (KGS), "Final report of project on investigating the causes and the establishing restoration of landslides in Mt. Woomyeon (KGS11-250),” Korean Geotechnical Society (KGS), Seoul Metropolitan City, Republic of Korea, in Korean, 2011.

[3] B. G. Chae, Y. S. Song, Y. S. Seo, Y. C. Cho, and W. Y. Kim, "A test for characterization on landslides triggering and flow features of debris using a flume test equipment," The Journal of Engineering Geology, vol. 16, no. 3, pp. 275-282, 2006, in Korean.

[4] B. G. Chae, S. H. Lee, Y. S. Song, Y. C. Cho, and Y. S. Seo, "Characterization on the relationships among rainfall intensity, slope angle and pore water pressure by a flume test: in case of gneissic weathered soil," The Journal of Engineering Geology, vol. 17, no. 1, pp. 57-64, 2007, in Korean.

[5] Y. S. Song, B. G. Chae, and Y. S. Seo, "Proposal of method to estimate the runout distance of landslides induced by rainfall," Journal of the Korean Society of Civil Engineers, vol. 27, no. 5C, pp. 343-352, 2007, in Korean.

[6] K. Lee, H. Han, D. Chang, and D. Yoon, "Seepage behavior by artificial rainfall in weathered granite model slope," Journal of the Korean Geoenvironmental Society, vol. 14, no. 12, pp. 5-12, 2013, in Korean.

[7] D. Kim, J. Seo, C. Lee, and C. Woo, "Analysis on the behaviors of soil water characteristic sensors through rainfall-induced landslide flume experiments," Korean Society of Hazard Mitigation, vol. 16, no. 6, pp. 209-218, 2016, in Korean.

[8] W. N. Chien, R. H. Woo, and K. J. Kuo, "Failure mechanism of granular soil slopes under high intensity rainfalls," Journal of Geo Engineering, vol. 7, no. 1, pp. 21-31, 2012.

[9] Q. Ran, D. Su, P. Li, and Z. He, "Experimental study of the impact of rainfall characteristics on runoff generation and soil erosion," Journal of Hydrology, vol. 424-425, pp. 99-111, 2012.

[10] G. Acharya, T. A. Cochrane, T. Davies, and E. Bowman, "The influence of shallow landslides on sediment supply: a flumebased investigation using sandy soil," Engineering Geology, vol. 109, no. 3-4, pp. 161-169, 2009.

[11] C. Gallage, S. Jayakody, and T. Uchimura, "Effect of slope inclination on the rain-induced instability of embankment slopes," in Proceedings of the 2nd International Conference on Geotechnique, Construction Materials and Environment, pp. 196-201, Kuala Lumpur, Malaysia, 2012.

[12] S. D. N. Lourenço, G.-H. Wang, and T. Kamai, "Processes in model slopes made of mixtures of wettable and water repellent sand: implications for the initiation of debris flows in dry slopes," Engineering Geology, vol. 196, pp. 47-58, 2015. 
[13] R. M. Iverson, M. E. Reid, N. R. Iverson et al., "Acute sensitivity of landslide rates to initial soil porosity," Science, vol. 290, no. 5491, pp. 513-516, 2000

[14] H. Moriwaki, T. Inokuchi, T. Hattanji, K. Sassa, H. Ochiai, and G. Wang, "Failure processes in a full-scale landslide experiment using a rainfall simulator," Landslides, vol. 1, no. 4, pp. 277-288, 2004.

[15] M. E. Reid, R. G. LaHusen, and R. M. Iverson, "Debris-flow initiation experiments using diverse hydrologic triggers," in Proceedings of the 1st International Conference on Debris-Flow Hazards Mitigation: Mechanics, Prediction and Assessment, C. L. Chen, Ed, American Society of Civil Engineers, San Francisco, CA, USA, pp. 1-11, 1997.

[16] S. D. Lourenço, K. Sassa, and H. Fukuoka, "Failure process and hydrologic response of a two layer physical model: implications for rainfall-induced landslides," Geomorphology, vol. 73, no. 1-2, pp. 115-130, 2006.

[17] Y.-S. Song and W.-K. Hwang, "Numerical study of unsaturated infinite slope stability regarding suction stress under rainfall-induced infiltration conditions," The Journal of Engineering Geology, vol. 24, no. 1, pp. 1-8, 2014.

[18] Y. S. Song, N. W. Lee, W. K. Hwang, and T. H. Kim, "Construction and application of an automated apparatus for calculating the soil-water characteristic curve," Journal of Engineering Geology, vol. 20, no. 3, pp. 281-295, 2010, in Korean.

[19] M. T. van Genuchten, "A closed-form equation for predicting the hydraulic conductivity of unsaturated soils," Soil Science Society of America Journal, vol. 44, no. 5, pp. 892-898, 1980.

[20] Y. Mualem, "A new model for predicting the hydraulic conductivity of unsaturated porous media," Water Resources Research, vol. 12, no. 3, pp. 513-522, 1976.

[21] S. K. Kim, W. P. Hong, and Y. M. Kim, "Prediction of rainfalltriggered landslides in Korea," in Proceedings of the International Symposium on Landslides, pp. 989-994, Rotterdam, Netherlands, February 1992.

[22] L. Z. Wu, Y. Zhou, P. Sun, J. S. Shi, G. G. Liu, and L. Y. Bai, "Laboratory characterization of rainfall-induced loess slope failure," Catena, vol. 150, pp. 1-8, 2017.

[23] R. M. Iverson, "The physics of debris flows," Reviews of Geophysics, vol. 35, no. 3, pp. 245-296, 1997.

[24] R. M. Iverson, "Scaling and design of landslide and debrisflow experiments," Geomorphology, vol. 244, pp. 9-20, 2015.

[25] G. G. D. Zhou and C. W. W. Ng, "Dimensional analysis of natural debris flows," Canadian Geotechnical Journal, vol. 47, no. 7, pp. 719-729, 2010.

[26] C. W. W. Ng, C. E. Choi, J. S. H. Kwan, R. C. H. Koo, H. Y. K. Shiu, and K. K. S. Ho, "Effects of baffle transverse blockage on landslide debris impedance," Procedia Earth and Planetary Science, vol. 9, pp. 3-13, 2014. 